\title{
A Contribuição da Coordenação Pedagógica na Escola de Medicina
}

\author{
The Contribution of Pedagogic \\ Coordination in Medical Teaching
}

Valter Carabetta Júnior ${ }^{1}$ Maria Cristina F. da S. Cury ${ }^{1}$

PALAVRAS-CHAVE:

- Ensino;

- Aprendizagem;

- Educação Médica.

KEY-WORDS

-Teaching;

-Learning;

-Education, Medical.

Recebido em: 01/11/2005

Reencaminhado em:23/10/2006

Aprovado em: 11/01/2007

\section{RESUMO}

A maioria dos professores que ministram aulas nos cursos de Medicina "não são professores", mas "estão professores", pois não receberam, na formação acadêmica, fundamentos pedagógicos que Ihes possibilitem entender e interpretar o processo ensino-aprendizagem. A partir desse pressuposto, a instituição do trabalho de Coordenação Pedagógica nesse curso pode constituir um caminho para a reflexão, supervisão e direcionamento da prática docente, possibilitando instrumentalizar e ampliar os horizontes de atuação do professor num momento em que se repensa a educação médica necessária para atender as exigências da sociedade atual, resgatando a visão holística do ser humano e o incremento da relação médico-paciente.

\begin{abstract}
The aim of this paper was to make some reflections upon the role and the value of pedagogic coordination in medical teaching. It starts from the presumption that the greater part of lecturers giving classes in medical schools are not really professors, they are only acting as such. The academic formation of these lecturers did not provide adequate pedagogical bases allowing them to understand and interpret the teaching-learning process. Thus, implementing pedagogic coordination in the medical course could represent a way towards reflection, supervision and ideal direction besides allowing to widen the horizons of the teaching practice, particularly these days when medical education is being reviewed so it can meet the needs of modern society with an integrated and global vision of the human being and improving the doctor-patient relationship.
\end{abstract}


(...) quem forma se forma e re-forma ao formar e quem é formado forma-se e forma ao ser formado. É neste sentido que ensinar não é transferir conhecimentos, conteúdos, nem formar é ação pela qual um sujeito criador dá forma, estilo ou alma a um corpo indeciso e acomodado. Não há docência sem discência, as duas se explicam e seus sujeitos, apesar das diferenças que os conotam, não se reduzem à condição de objeto, um do outro. Quem ensina aprende

ao ensinar e quem aprende ensina ao aprender. Quem ensina ensina alguma coisa a alguém. Por isso é que, do ponto de vista gramatical, o verbo ensinar é transitivo-relativo. Verbo que pede um objeto direto - alguma coisa - e um objeto indireto - a alguém.

Paulo Freire - Pedagogia da Autonomia

\section{A REFLEXÃO COMO CAMINHO PARA A REVISÃO E (RE)ELABORAÇÃO DA PRÁTICA DOCENTE}

Atualmente, o conhecimento é concebido como fator primordial do novo paradigma econômico, sendo imprescindível para gerar riquezas, explicitando-se com muita nitidez sua imediata relação com o universo do trabalho. Nesse cenário, a importância da educação para a distribuição eqüitativa dessa riqueza tem sido reconhecida e valorizada, e as universidades, como principais centros de construção e de circulação do conhecimento, assumem papel de destaque ${ }^{1}$.

A Conferência Mundial sobre Educação Superior no Século XXI, realizada em Paris em 1998, evidenciou que, devido ao alcance e ao ritmo em que ocorrem as transformações, a sociedade tende, cada vez mais, a se fundamentar no conhecimento. Por essa razão, hoje em dia, a educação superior e a pesquisa são essenciais ao desenvolvimento cultural, social e econômico das comunidades e nações.

Assim, a produção do conhecimento que ocorre na universidade precisa satisfazer, em termos teóricos e práticos, a qualificação do profissional que está sendo formado. Nesse sentido, não se pode pensar em formar profissionais capazes se os docentes não estão conscientes da responsabilidade que têm e tampouco reflexivos em relação a uma prática pedagógica significativa e eficiente.

A palavra reflexão vem do latim reflectere, que quer dizer "voltar atrás"; portanto, refletir significa rever, retomar, repensar, reexaminar de maneira crítica o que já foi feito. A reflexão, como mediadora de transformação, possibilita avaliar a prática com o objetivo de analisá-la e contextualizá-la, retornando a ela a fim de reforçá-la ou reconduzi-la. Há a necessidade estratégica de sairmos do imediato para podermos olhar sob outro prisma alguns elementos que já conhecemos.

Refletir sobre as necessidades e dificuldades existentes na qualificação do ensino significa preocupar-se com a legitima- ção do conhecimento como fundamental para o desenvolvimento intelectual e para o exercício consciente da cidadania. Trata-se, portanto, de buscar uma docência significativa, participativa e inovadora, o que demanda do professor competência teórico-prática da disciplina para a seleção, análise, interpretação e avaliação dos objetivos pretendidos e dos conteúdos conceituais, procedimentais e atitudinais que serão trabalhados.

Em nosso cotidiano, é importante manter um distanciamento que oportunize reflexões construtivas para a melhoria da prática docente. Um olhar crítico para a realidade torna-se essencial para desvelarmos situações e caminhos que possam ser contornados com maior segurança, efetividade e sem constrangimentos, objetivando um crescimento pessoal e profissional2.

Isto é especialmente relevante quando se trata da educação superior, que parece resistir aos novos tempos, às mudanças e exigências sociais, apresentando como característica a exploração de grande quantidade de conteúdos, muitas vezes desarticulados internamente e sem interligações com outras disciplinas, consistindo a aula na simples, constante e monótona transmissão de informações, na grande maioria das vezes, descontextualizadas.

De acordo com o artigo 43 da Lei 9.394/96 de Diretrizes e Bases da Educação Nacional (LDB), constituem objetivos da educação superior:

I - estimular a criação cultural e o desenvolvimento do espírito científico e do pensamento reflexivo;

II - formar diplomados nas diferentes áreas de conhecimento, aptos para a inserção em setores profissionais e para a participação no desenvolvimento da sociedade brasileira, e colaborar na sua formação contínua;

III - incentivar o trabalho de pesquisa e investigação científica, visando o desenvolvimento da ciência e da tecnologia e da criação e difusão da cultura, e, desse modo, desenvolver o entendimento do homem e do meio em que vive;

IV - promover a divulgação de conhecimentos culturais, científicos e técnicos que constituem patrimônio da humanidade e comunicar o saber através do ensino, de publicações ou de outras formas de comunicação;

$\mathrm{V}$ - suscitar o desejo permanente de aperfeiçoamento cultural e profissional e possibilitar a correspondente concretização, integrando os conhecimentos que vão sendo adquiridos numa estrutura intelectual sistematizadora do conhecimento de cada geração;

VI - estimular o conhecimento dos problemas do mundo presente, em particular os nacionais e regionais, prestar 
serviços especializados à comunidade e estabelecer com esta uma relação de reciprocidade;

VII - promover a extensão, aberta à participação da população, visando à difusão das conquistas e benefícios resultantes da criação cultural e da pesquisa científica e tecnológica geradas na instituição ${ }^{3}$.

Constatamos que os objetivos citados acima se opõem a uma proposta pedagógica acrítica, passiva, descontextualizada, mnemônica e individualista; a um modelo didático centrado no professor, com aulas puramente expositivas em que o monólogo perfaz a maior parte, senão toda a aula, ficando os alunos limitados a ouvir e/ou copiar o que está sendo exposto pelo professor.

Os objetivos da educação superior levam-nos, assim, a considerar a necessidade de ruptura com um ensino tradicional para ressignificar a ação educativa na universidade, investindo num processo pedagógico que possibilite a excelência na operacionalização da continuidade da construção do conhecimento pelos alunos; um processo pedagógico em que o aluno esteja envolvido nas atividades, constituindo um elemento de produção educativa.

No processo pedagógico, o aluno precisa participar das atividades desenvolvidas como objeto e como sujeito da educação. Afirmar que o aluno é o objeto da educação significa considerá-lo como verdadeiro objeto de trabalho do processo produtivo escolar, já que ele constitui a própria realidade sobre a qual se aplica o trabalho humano, com vistas à realização do fim educativo ${ }^{4}$.

Neste foco, vemos que a conscientização sobre a necessidade de mudança da atuação docente e a realidade dessa ação ainda estão incompatíveis num sistema que deve ter como objetivo a criação de uma prática pedagógica que possibilite o estabelecimento de relações entre estruturar conhecimentos teoricamente sistematizados e as questões da vida real, ampliando saberes e promovendo o desenvolvimento da pesquisa, do raciocínio lógico e uma compreensão abrangente dos diferentes objetos de conhecimento, pois "toda ação docente extrai sua consistência de uma articulação simbiótica com o discurso pedagógico, sendo o par ação/discurso tributário de uma concepção de conhecimento" ${ }^{\prime \prime}$.

O ensino universitário ainda continua a investir na reprodução de conhecimentos já elaborados, quando deveria empreender a procura de novos conhecimentos, o que evidencia uma inércia no sentido do exercício da crítica epistemológica. É essa inércia que privilegia comportamentos reprodutivistas, que inviabilizam a busca da reconstrução metodológica contínua ${ }^{6}$.
Se nos apoiarmos na perspectiva da epistemologia genética, a ação educativa não deve ser considerada como simples instrumentalização, como técnica, mas como formadora de conhecimentos, atitudes e valores por meio de um trabalho com objetivos claramente definidos e metodologia adequada aos ideais propostos. Numa nova configuração pretendida para a educação universitária, torna-se relevante o investimento na formação do professor na tradução de competências relacionadas aos valores éticos; a socialização e significação dos conteúdos em diferentes contextos e de sua articulação interdisciplinar, bem como o conhecimento pedagógico e dos processos de investigação que possibilitam o aperfeiçoamento da prática docente.

\section{O PENSAR E O FAZER PEDAGÓGICO NA ESCOLA MÉDICA}

Tomando-se como referência a escola de Medicina, podemos afirmar que, com algumas exceções, a maioria dos docentes "estão professores" e "não são professores", pois não tiveram formação pedagógica em suas faculdades de origem. Isto os impede de ter maior desenvoltura no entendimento e aplicação de aspectos teóricos e práticos do ensino e aprendizagem.

Considerando inerente vincular o saber pedagógico na escola de Medicina, Moura ${ }^{7}$ deixa evidente que, pelo fato de ser médico, isto não significa que o portador de determinado saber possa ser considerado um professor de Medicina, pois os professores aprendem a lidar com pessoas colocando-as em posição de aprendizes, desenvolvendo atitudes de educadores. Estes podem ser qualificados como os que têm ou não didática, isto é, existe um senso comum sobre quem pode ser considerado um bom professor: ter didática - esta entendida como um modo de organizar o ensino para favorecer a aprendizagem.

Essa organização proporcionada pela didática deve compreender a construção das bases teórico-metodológicas para a organização e desenvolvimento dos conteúdos curriculares e para a elaboração e processamento das avaliações.

Desse modo, por mais qualificados que sejam os professores em relação ao conteúdo específico de sua disciplina, "não há garantia de que a mesma tenha igual peso na construção do significado, dos saberes, das competências, dos compromissos e das habilidades referentes à docência e de que estejam preparados para conceber e implementar alternativas e soluções pedagógicas adequadas, diante dos problemas que surgem na aprendizagem de seus alunos"8.

Para Batista ${ }^{9}$, o problema da capacitação do docente de Medicina em relação aos aspectos pedagógicos da profissão não tem recebido a atenção necessária. Ao contrário de ou- 
tras áreas do conhecimento, como no caso das ciências humanas, na formação do médico não se objetiva a preparação de um professor.

Feuerwerker ${ }^{10}$ reforça a observação sobre a falta de preparo do docente de Medicina para o magistério considerando que nas escolas médicas não existe preparo específico no terreno pedagógico. A competência na área técnica de atuação médica é o critério fundamental para a escolha dos profissionais que irão passar de médico a professor, prevalecendo uma concepção de ensino tradicional, baseada na transmissão do conhecimento e na experiência do professor, com supervalorização dos conteúdos disciplinares e reprodução desses conteúdos pelos alunos.

Indo ao encontro do pensamento de Zeichner ${ }^{11}$ - para quem o trabalho educacional requer que os professores assumam uma postura reflexiva sobre sua prática e as condições sociais vigentes que a influenciam -, entendemos que no trabalho docente deve existir inter-relação entre o pleno conhecimento do conteúdo referente à disciplina ministrada e como os diferentes conteúdos devem ser trabalhados em sala de aula. Para isso, é necessário oferecer aos professores um suporte pedagógico que lhes possibilite uma articulação entre ação-reflexão-ação, visando a uma atuação mais significativa e segura no exercício do magistério.

Na prática, é preciso considerar que tão importante quanto alimentar o conhecimento acadêmico é sua efetiva apropriação pelos alunos, e a tarefa fundamental do professor é elaborar estratégias de emergência de conhecimentos tácitos, resultantes tanto de atividades escolares quanto de suas vivências em ambientes extracurriculares ${ }^{1}$.

Vivemos um momento histórico que considera o conhecimento científico como o conhecimento autêntico; um momento em que presenciamos um vertiginoso desenvolvimento científico e tecnológico. Com pesquisas cada vez mais qualificadas e sofisticadas, descobrem-se e criam-se coisas antes impensadas: projeto genoma humano, células-tronco, clonagem, projeto proteoma, transgênicos, terapia genética, nanotecnologia, etc. Novas ciências, como a farmacogenética e a bioinformática, surgem como produto do aprofundamento e das inter-relações de conhecimentos, e a crescente popularização da atividade científica permite que certos termos, antes restritos ao ambiente acadêmico, façam parte do vocabulário da população.

Segundo Singer ${ }^{12}$ :

"A valorização da ciência é tanto cultural quanto econômica. Governos e empresas, nos países desenvolvidos e semidesenvolvidos, demandam mais pesquisa científica e se dispõem a pagar por ela. A corrida tecnológica entre as maiores transnacionais se acirra, o que acarreta a multiplicação de laboratórios e centros de investigação, tanto em firmas privadas como em instituições públicas, inclusive em universidades. Até recentemente, grande parte do desenvolvimento de novas tecnologias se fazia por tentativa e erro, em pequenas oficinas comandadas por inventores. Agora, o desenvolvimento tem por pressuposto novas descobertas, feitas por especialistas em universidades e grandes empresas" 12 .

A quantidade de novas informações e conhecimentos sobre Biologia veiculada pela imprensa especializada é tão grande, que a plena atualização se torna praticamente impossível. Todo esse conhecimento, em constante revolução, possibilita à Medicina fazer diagnósticos e tratamentos cada vez mais precisos e eficientes.

Se, por um lado, os avanços da Biologia proporcionam maior segurança ao paciente e aos encaminhamentos médicos, por outro, estamos vivenciando uma Medicina técnica, descaracterizada de sua arte, constatada pela modificação da relação médico-paciente. Já não é freqüente a prática do exame clínico, pois a máquina confere maior praticidade e segurança diagnóstica: é possível imaginar a prescrição de lentes por um oftalmologista sem passar pela precisão avaliativa dos aparelhos usados na consulta?; a observação de detalhes de células e tecidos sem o poder de resolução proporcionado pela microscopia eletrônica?; ou, ainda, a não utilização da tomografia computadorizada ou da ressonância magnética em casos em que há necessidade de complementar e resolver uma suspeita médica?

Com a prática médica cada vez mais apoiada na tecnologia, constata-se uma perda significativa para o raciocínio clínico com base em dados coletados por meio da semiologia, tornando-se necessário que as escolas médicas reflitam se pretendem que os estudantes desenvolvam habilidades clínicas ou de leitura de exames ${ }^{13}$.

Porém, por mais que se faça uso da tecnologia, o poder de decisão continua sendo do médico. Daí, a importância da boa formação acadêmica para o desenvolvimento de competências para saber decidir, encaminhar e acompanhar determinado paciente.

A competência da ação pode ser entendida como a capacidade de mobilizar diferentes possibilidades cognitivas para agir de maneira conveniente na resolução de problemas. Para desenvolver competências nos estudantes, há necessidade de uma transformação da relação do professor com o saber, de sua maneira de estruturar as aulas, de sua identidade e de suas próprias competências profissionais. Nessa perspectiva, 
o gerenciamento da contínua formação docente garante a constante atualização e adaptação dos recursos cognitivos às condições de trabalho em evolução ${ }^{14}$.

A especialização do conhecimento científico ocasionou o aparecimento de subespecializações na ciência que fragmentaram e departamentalizaram o conhecimento, dificultando o olhar interdisciplinar. E, como sabemos, poucos são os diálogos que as diferentes disciplinas mantêm entre si, impedindo que o aluno desenvolva uma visão integrada do conhecimento para poder estabelecer relações conceituais.

Como aponta Feuerwerker ${ }^{10}$ :

"Do ponto de vista da abordagem dos problemas de saúde, a utilização dos especialistas como porta de entrada do sistema implica vários problemas. Sabe-se que para problemas comuns (que poderiam ser abordados e resolvidos por um generalista), o olhar do especialista, além de ser fragmentado e incompleto, é mais oneroso (desnecessariamente são pedidos mais exames, exames mais sofisticados, utilizam-se recursos terapêuticos mais caros e requintados, sem que exista diferença positiva nos resultados)"10.

Para a relação médico-paciente, a fragmentação da atenção implicou a falta ou a redução de vínculos, diminuindo o envolvimento dos profissionais em relação à saúde geral do paciente, bem como a insatisfação do usuário sobre a atenção que recebe ${ }^{10}$.

Embora a função do especialista seja fundamental em determinadas situações, é indispensável conservar a visão do conjunto. A restrição ao especialista deve ser feita contra a mente especializada, de perspectiva estreita, que exclui a pessoa do paciente de sua própria doença a ser estudada ${ }^{15}$.

Para Alves ${ }^{16}$, a especialização gerada pelo conhecimento científico pode se transformar numa perigosa fraqueza, pois, quanto maior for a visão em profundidade, menor será a visão em extensão, já que a tendência da especialização é conhecer cada vez mais de cada vez menos.

Lampert17 considera que, apesar de a fragmentação do conhecimento, que resultou nas diferentes especializações, ter ampliado e aprofundado o conhecimento, ocasionou a limitação da visão e o distanciamento do ser humano do seu contexto, chamando a atenção para a necessidade de uma formação em saúde que considere o ser humano de maneira integral, interdisciplinar, multiprofissional e justa.

Demo $^{18}$, por sua vez, observa:

"A possibilidade de uma compreensão integral do ser humano e do processo saúde-doença, objeto do trabalho em saúde, passa necessariamente por uma abordagem interdisciplinar e por uma prática multiprofissional. Abor- dagem interdisciplinar na construção do conhecimento, chegando, pelo menos, a interações recíprocas e à colaboração entre disciplinas diversas. Abordagem interdisciplinar que implique na demolição das fronteiras entre pesquisa e ensino-aprendizagem"18.

Neste sentido, para Machado ${ }^{13}$, a especialização é um meio estratégico para controlar os avanços científicos a fim de assegurar o domínio de conhecimentos específicos e da prática profissional, o que tende a provocar o abandono do conhecimento generalista.

Na concepção de Gourgen ${ }^{19}$, a divisão do conhecimento em disciplinas e especialidades tem um sentido prático e não pode ser evitada nas condições atuais devido à grande quantidade de novos conhecimentos gerados. Porém, deve-se estar consciente de que toda divisão do conhecimento é formal e não corresponde à realidade, que é orgânica, integrada e indivisa. Pensar numa perspectiva integrada deve nascer do interior de cada disciplina por meio de uma abordagem que coloca a especialidade no horizonte de seu desenvolvimento histórico como parte de um todo maior.

Essa visão fragmentada do ser humano ocorre porque, na maioria das escolas médicas brasileiras, ainda continuamos a presenciar uma estrutura curricular atrelada às recomendações do Relatório Flexner, publicado em 1910, caracterizado pela divisão em disciplinas básicas e clínicas, destacando-se a importância das especializações e dos departamentos e enfatizando-se os aspectos puramente biológicos, presenciando-se, assim, a separação entre corpo e mente.

Em relação ao desempenho dos alunos de cursos de $\mathrm{Me}-$ dicina, Souza e Rangel ${ }^{20}$ observam que a Comissão Interinstitucional de Avaliação do Ensino Médico (Cinaem), por meio de um projeto que objetiva avaliar a formação desses alunos, constatou que, ao término do curso, o resultado esperado para o desenvolvimento cognitivo dos alunos deixou a desejar. Após realizarem vários estudos sobre a causa desse problema, as autoras alegaram que ficou evidenciada a presença de elementos de um modelo pedagógico ultrapassado, em que persiste a fragmentação entre teoria e prática, a falta de integração entre conteúdos e a centralização das atividades no professor.

Segundo Lampert ${ }^{17}$, é preciso instituir um novo modelo pedagógico para a educação médica, como proposto pelo paradigma da integralidade ${ }^{21}$, visando a: a) centralizar o processo ensino-aprendizagem no aluno, destacando seu papel ativo neste processo; b) uma capacitação docente voltada para a competência técnico-científica e didático-pedagógica, bem como para maior participação e compromisso com o sistema 
público de saúde; c) maior ênfase na saúde do que na doença; d) que o ensino da prática ocorra no sistema de saúde existente em graus crescentes de complexidade; e) o acompanhamento da dinâmica do mercado de trabalho por meio da reflexão e discussão crítica dos aspectos econômicos e humanos da prestação de serviços de saúde e de suas implicações éticas.

Com o paradigma da integralidade objetiva-se, assim, pensar e integrar aspectos científicos, culturais, sociais e econômicos para estabelecer uma relação igualitária entre o social e a qualificação técnica.

Porém, para haver mudança de paradigma, o papel do professor de Medicina precisa ser revisto no sentido de inovar a metodologia de trabalho a fim de viabilizar um ensino motivador, humanista, interativo e significativo, deixando o professor de ser um simples emissor de informações para se assumir como articulador entre a ciência e o aluno. Para tanto, a dinâmica pedagógica tem de estar comprometida em proporcionar aos alunos o desenvolvimento da iniciativa, da dialogia, do trabalho em equipe, o estímulo à pesquisa, o estabelecimento de relações e a tomada de decisões.

Para uma nova dinâmica pedagógica, o professor precisa estar ciente e consciente de que a aprendizagem requer articulação epistemológica e prática, em que a significação dada àquilo que se aprende é o fulcro do processo. Nessa direção, pensar um ensino médico em que a problematização e a interdisciplinaridade se fazem presentes - permitindo a investigação e análise teórica e prática de problemas da realidade social e a interação entre as disciplinas, rompendo, assim, com a departamentalização de conhecimentos - pode constituir um caminho para a mudança.

Nesse sentido, concordamos com Piaget ${ }^{22}$ quando afirma que é preciso revisar os métodos e o espírito do ensino para adaptá-lo às exigências da sociedade, sendo necessário que o educador planeje e conceba situações capazes de promover problemas úteis aos alunos, levando-os à reflexão, e que assuma o papel de elemento estimulador do pensamento e da pesquisa, abandonando a postura de conferencista para quem a transmissão de soluções encontra-se pronta.

Compactuamos com o ideal de um curso de Medicina cuja estruturação objetive a formação de um profissional generalista, humanista, crítico e reflexivo, capacitado a atuar na perspectiva da integralidade nos diferentes níveis de atenção do processo saúde-doença, com intervenções capazes de promover, prevenir, recuperar e reabilitar a saúde, com responsabilidade ética e social e compromisso com a cidadania, promovendo a saúde do ser humano ${ }^{20}$.

Na formação do médico, é necessário desenvolver um ensino que possibilite ampliar "seu alerta perceptivo e enxer- gar com isto um outro paciente, que tem um primeiro corposuporte, sobre o qual projeta e amalgama as distrofias de seu outro corpo, o corpo matéria, informacional, cultural, social, histórico, um corpo semiótico, feito de sinais e símbolos, de histórias e lendas, de imaginação e fantasia, de sonhos e brincadeiras, de jogos e papéis sociais, de personagens imaginárias, de mitos e de crenças, do vivido e do desejado, dos saberes e dos sabores, dos seus temores e ansiedades, enfim um corpo feito também das suas paixões" 23 .

\section{O PAPEL E O VALOR DA COORDENAÇÃO PEDAGÓGICA}

A palavra coordenação encontra-se vinculada à idéia de organização, de ação efetiva, no sentido de realizar trabalho voltado para a construção da identidade coletiva ou para o reconhecimento recíproco do trabalho e das competências de $\operatorname{todos}^{14}$.

Assim, levando-se em conta a necessidade de oferecer instrumentalização para: aprimorar a atuação do professor na elaboração e encaminhamento de questões pedagógicas; realizar o acompanhamento e orientação de alunos; encaminhar a criação de diferentes estratégias de avaliação; dirigir e supervisar o trabalho desenvolvido em sala de aula; articular a construção coletiva e viabilização do projeto pedagógico da instituição e orientar a elaboração dos planejamentos de ensino, é que se faz oportuna a presença da Coordenação Pedagógica na escola de Medicina.

Para garantir o respeito aos princípios e diretrizes contidos na proposta educacional, o trabalho da Coordenação Pedagógica requer experiência educativa, isto é, visão ampla do processo educacional e experiência técnica relacionada à administração escolar, para contribuir na resolução de problemas inerentes à prática pedagógica, tais como planejamento educacional, processo de avaliação, oferecimento de subsídios que possam unir a competência técnico-científica à didático-pedagógica e implantar e supervisionar mudanças acordadas pelo corpo docente.

O trabalho desenvolvido pela Coordenação Pedagógica deve ser exercido basicamente na vivência da dimensão do encontro e do diálogo. Muitos são os encontros que ocorrem na escola, sendo que o mais importante é o do aluno com o conhecimento. No entanto, para que ele aconteça, é fundamental que existam outros encontros, entre eles o do coordenador com o professor ${ }^{24}$.

Partimos do pressuposto de que a Coordenação Pedagógica na escola médica pode se converter num caminho para a reflexão, orientação e redirecionamento da prática docente, possibilitando instrumentalizar e ampliar os horizontes de 
atuação profissional num momento em que se repensa a educação médica necessária para contemplar as exigências da atual sociedade, resgatando a visão holística do ser humano e a melhora da relação médico-paciente.

Em nosso entender, o trabalho desenvolvido na escola de Medicina deve estar voltado para uma prática pedagógica que origine e amplie nos estudantes uma sólida formação científica, humanista e ética, objetivando formar profissionais que desenvolvam competências para a resolução tanto dos problemas básicos de saúde, como dos específicos, nas diferentes especialidades médicas.

Na capacitação docente, temos como referência o alinhamento entre a formação do professor e o desenvolvimento de uma prática motivadora e significativa, possibilitando que o professor tenha clareza em relação aos objetivos pretendidos em sua disciplina; a importância da seleção de conteúdos na formação do aluno; a necessidade de articulação entre conteúdos, métodos e técnicas, das possibilidades de ações didáticas com os diferentes assuntos e de como diagnosticar a aprendizagem por meio de uma avaliação qualificada.

Porém, cabe destacar que, sem o consenso e o esforço conjunto, apenas o trabalho da Coordenação Pedagógica não tem significado e não produz efeitos positivos. É preciso que os professores estejam conscientes e dispostos a assumirem uma atitude de mudança em relação a crenças e valores das práticas educativas, e estarem comprometidos com o desenvolvimento de novas competências para uma reorientação da prática educativa em sala de aula.

Se objetivamos uma educação médica comprometida com uma conduta em que o aluno seja sujeito de sua aprendizagem, que o leve a aprender a aprender e a saber-fazer e que forme profissionais qualificados do ponto de vista científico e humanista para que possam cumprir seu papel na sociedade, temos que reconsiderar os conhecimentos necessários à atuação docente, pensando cada vez mais nas contribuições da Pedagogia na orientação da prática. Como afirma Luckesi ${ }^{25}$, atualmente esta ciência se encontra suficientemente amadurecida para fornecer subsídios ao planejamento e desenvolvimento de uma prática educativa capaz de obter resultados cada vez mais significativos no processo ensino-aprendizagem.

\section{REFERÊNCIAS}

1. Machado N.J. A universidade e a organização do conhecimento: a rede, o tácito e a dádiva. Estudos Avançados 2001;15:333-352.

2. Rios T.A. Significado e pressupostos do projeto pedagógico. In: Rios T.O. Diretor: articulador do projeto da escola. São Paulo: FDE; 1992.p.73-77. [Série Idéias]
3. Brasil. Ministério de Educação e Cultura. Lei de Diretrizes e Bases da Educação Nacional. São Paulo: Brasília: MEC; 1996.

4. Paro V.H. Administração de escolas de $1^{\mathrm{o}}$ e $2^{\underline{o}}$ graus e a natureza do processo de produção pedagógico. Cadernos de Pesquisa 1986; 59: 27-31.

5. Machado N. Epistemologia e didática. São Paulo: Cortez; 1995.

6. Becker, F. Construtivismo: apropriação pedagógica In: Rosa D E, Gonçalves e Souza, Vanilton C, orgs. Didática e práticas de ensino: interfaces com diferentes saberes e lugares formativos. Rio de Janeiro: DP\& A; 2002. p. 102-138.

7. Moura M.O. de. A atividade de ensino como ação formadora. In: Castro, A D, Carvalho, A M. P. de, orgs. Ensinar a ensinar: didática para a escola fundamental e média. São Paulo: Pioneira Thompson Learning; 2001. p. 143-162.

8. Anastasiou L. das G.C. Construindo a docência no ensino superior: relação entre saberes pedagógicos e saberes científicos. In: Rosa, D.E.G, Souza, V.C. Didática e práticas de ensino: interfaces com diferentes saberes e lugares formativos. Rio de Janeiro/Goiânia: DP\&A editora/Editora Alternativa; 2002. p.173-187.

9. Batista N.A. Formação do professor de Medicina: desafios e perspectivas. In: Marcondes, E.; Gonçalves, E.L.. Educação Médica. São Paulo: Sarvier; 1998.

10. Feuerwerker L. Além do discurso de mudança na educação médica: processos e resultados. São Paulo/ Londrina/ Rio de Janeiro: Hucitec / Rede Unida;2001.

11. Zeichner K. Formação reflexiva de professores. Lisboa: Educa; 1993.

12. Singer P. A universidade no olho do furacão: estudos Avançados 42.São Paulo: Instituto de Estudos Avançados USP; 2001. p. 305 a 316. [Dossiê Educação]

13. Machado M.H., Rego, S.T.A. Os médicos no Brasil: um retrato da realidade. Boletim ABEM; 1997.

14. Perrenoud P. Dez novas competências para ensinar. Porto Alegre: Artmed; 2000.

15. Blasco P.G. O médico de família hoje. São Paulo: SOBRAMFA; 1997.

16. Alves R. Filosofia da ciência. São Paulo: Editora Brasiliense; 1981.

17. Lampert J.B. Tendências de mudanças na formação médica no Brasil. São Paulo: Hucitec; 2002.

18. Demo P. Desafios modernos da educação. Petrópolis: Vozes; 1998. 
19. Gourgen P. Ensino superior e formação cidadã: elementos para uma avaliação crítica. Campinas: PUC; 2004.p.5-31. [Série Acadêmica, 18]

20. Souza M. P. G. de, Rangel M. Avaliação: um impasse na educação médica. Rev. Bras. Educ Méd. 2003; 27:213-222.

21. Campos F.E. et al. Caminhos para aproximar a formação de profissionais de saúde das necessidades da atenção básica. Rev. Bras. Educ. Méd.2001; 25:53-59.

22. Piaget J. Para onde vai a educação? Rio de Janeiro: José Olympio Editora; 1984.

23. Brasil. Conselho Nacional de Educação. Câmara de Educação Superior. Resolução CNE/CES 4/2001. Diário Oficial da União, Brasília, 9 de nov. de 2001; Seção 1, p. 38.

24. Furlanetto E.C. O papel do coordenador pedagógico na formação contínua do professor: dimensões interdisciplinares e simbólicas. In: Queluz A.G., org. Interdisciplinaridade: formação de profissionais da educação. São Paulo: Pioneira; 2000.

25. Luckesi C.C. Verificação ou avaliação: o que pratica a escola? São Paulo: FDE; 1990. [Idéias, 8]

\section{Conflito de interesse}

Declarou não haver

\section{Endereço para correspondência}

Faculdade de Medicina da Universidade de Santo Amaro - Unisa Rua Prof. Enéas de Siqueira Neto, 340 04829-300 - Jardim das Imbuias - Santo Amaro/SP e-mail: vcarabetta@unisa.com.br 